CORRECTION

https://doi.org/10.1038/s41586-019-1164-9

\title{
Publisher Correction: No detection of methane on Mars from early ExoMars Trace Gas Orbiter observations
}

Oleg Korablev, Ann Carine Vandaele, Franck Montmessin, Anna A. Fedorova, Alexander Trokhimovskiy, François Forget, Franck Lefèvre, Frank Daerden, Ian R. Thomas, Loïc Trompet, Justin T. Erwin, Shohei Aoki, Séverine Robert, Lori Neary, Sébastien Viscardy, Alexey V. Grigoriev, Nikolay I. Ignatiev, Alexey Shakun, Andrey Patrakeev, Denis A. Belyaev, Jean-Loup Bertaux, Kevin S. Olsen, Lucio Baggio, Juan Alday, Yuriy S. Ivanov, Bojan Ristic, Jon Mason, Yannick Willame, Cédric Depiesse, Laszlo Hetey, Sophie Berkenbosch, Roland Clairquin, Claudio Queirolo, Bram Beeckman, Eddy Neefs, Manish R. Patel, Giancarlo Bellucci, Jose-Juan López-Moreno, Colin F. Wilson, Giuseppe Etiope, Lev Zelenyi, Håkan Svedhem, Jorge L. Vago \& The ACS and NOMAD Science Teams

Correction to: Nature https://doi.org/10.1038/s41586-019-1096-4, published online 10 April 2019.

In the original Letter, owing to a typesetting error, an author name from the ACS and NOMAD Science Teams was incorrect: the surname of author Cathy Quantin-Nataf was misspelled 'Quantin-Nata'. In addition, authors Ehouarn Millour and Roland Young were inadvertently missing from the ACS and NOMAD Science Teams list. They are associated with Laboratoire de Météorologie Dynamique (LMD), CNRS Jussieu, Paris, France. Furthermore, the surname of Armin Kleinböhl was mispelled as Kleinbohl. Finally, the details for the Jet Propulsion Laboratory affiliation have been corrected. The original Letter has been corrected online. 